\title{
Helping women to good health: breast cancer, omega-3/omega-6 lipids, and related lifestyle factors
}

\author{
Michel de Lorgeril ${ }^{*}$ and Patricia Salen
}

\begin{abstract}
In addition to genetic predisposition and sex hormone exposure, physical activity and a healthy diet play important roles in breast cancer (BC). Increased intake of omega-3 fatty acids (n-3) associated with decreased omega-6 (n-6), resulting in a higher $n-3 / n-6$ ratio compared with the western diet, are inversely associated with $B C$ risk, as shown by Yang et al. in their meta-analysis in BMC Cancer. High consumption of polyphenols and organic foods increase the $n-3 / n-6$ ratio, and in turn may decrease BC risk. Intake of high fiber foods and foods with low glycemic index decreases insulin resistance and diabetes risk, and in turn may decrease $B C$ risk. The modernized Mediterranean diet is an effective strategy for combining these recommendations, and this dietary pattern reduces overall cancer risk and specifically BC risk. High-risk women should also eliminate environmental endocrine disruptors, including those from foods. Drugs that decrease the n-3/n-6 ratio or that are suspected of increasing BC or diabetes risk should be used with great caution by high-risk women and women wishing to decrease their BC risk.
\end{abstract}

Please see related article: http://www.biomedcentral.com/1471-2407/14/105/abstract.

Keywords: Polyphenols, Organic foods, Endocrine disruptors, Insulin, Diabetes, Cholesterol, Hypertension, Mediterranean diet

\section{Introduction}

Breast cancer $(\mathrm{BC})$ remains one of the commonest cancers - one in eight women will be diagnosed with $\mathrm{BC}$ in her lifetime [1] - and a leading cause of death from cancer. However, it remains a significant scientific and medical challenge. One of the crucial gaps identified is how to implement a sustainable preventive lifestyle strategy [2]. Both risk factors and protective factors must be considered. Some risk factors, such as genetic predisposition, cannot be modified, whereas others (unhealthy diet, sedentary lifestyle) can be avoided. Increasing protective factors may be crucial for women at high risk (as evaluated by the National Cancer Institute's (NCI's) BC Risk Assessment Tool [3]) and in preventing recurrence and improving survival after $\mathrm{BC}$ diagnosis. Decreasing the length of time a woman's breast tissue is exposed to estrogens may help prevent BC [1-3], although

\footnotetext{
* Correspondence: michel.delorgeril@ujf-grenoble.fr

Laboratoire TIMC-IMAG, CNRS UMR 5525, PRETA Cour and Nutrition, and Faculté de Médecine, Université Joseph Fourier, Grenoble, France
}

the main ways of achieving this (first pregnancy before the age of 20 years, breast feeding, late menstruation and early menopause) are difficult to control.

There are strong links between environmental/lifestyle factors and $\mathrm{BC}$, suggesting that modifying these factors may result in decreasing $\mathrm{BC}$ risk, although there has been no randomized trial that clearly demonstrated this. As changing these factors has been shown also to definitely reduce the risk of fatal diseases, notably cardiovascular diseases in randomized trials, it is reasonable to propose these changes to high-risk women and to women who wish to reduce their $\mathrm{BC}$ risk.

For instance, dietary fats have been extensively studied in the prevention of BC [4]. Neither animal fat nor a low-fat diet has been linked to $\mathrm{BC}$ risk, whereas marine omega-3 fatty acids (n-3) may be protective [4]. In a meta-analysis of 21 independent prospective cohort studies, Zheng et al. found a significant reduction of $\mathrm{BC}$ risk with marine $\mathrm{n}-3$ [5]. However, this meta-analysis highlights the difficulties in assessing the effects of specific dietary fats on BC risk. In 
subgroup analyses, Zheng et al. found that the inverse associations between marine $\mathrm{n}-3$ and $\mathrm{BC}$ risk were significant only in post-menopausal women, were stronger in East Asian populations compared with western populations and were more evident without adjustment for body mass index (BMI). This suggests that marine n-3 may influence $\mathrm{BC}$ risk partly through an effect on BMI or related factors (insulin or adipokines), whereas the importance of $\mathrm{BMI}$ on $\mathrm{BC}$ risk during the pre-menopausal and post-menopausal periods is still a matter of controversy [6]. The East Asian population issue suggests that other foods/nutrients and related factors may be involved. For instance, omega- 6 fatty acids (n-6) may play a role in BC risk [7]. It has long been suspected that $\mathrm{n}-6$ increase the risk of cancers, and this has been confirmed in controlled trials in which n-6 intakes were modified. In the Los Angeles Trial, there were more cancers in the experimental group with high n-6 intake, whereas in the Lyon Diet Heart Study, there were fewer cancers in the group with low $n-6[8,9]$. Thus, when analyzing the associations between $\mathrm{n}-3$ and $\mathrm{BC}$ risk, it is crucial that $\mathrm{n}-6$ is included in the analyses, as Yang et al. did in their recent study published in BMC Cancer [10].

\section{Breast cancer risk and $\mathrm{n}-3 / \mathrm{n}-6$ ratios}

Yang et al. used the ratio of $\mathrm{n}-3 / \mathrm{n}-6$ in a meta-analysis comprising 274,135 women with a total of $8,331 \mathrm{BC}$ events from 11 independent prospective studies [10]. Women with a higher $\mathrm{n}-3 / \mathrm{n}-6$ ratio had a significantly lower risk of $\mathrm{BC}$ : pooled RR 0.90, 95\% CI 0.82 to 0.99 . When the authors analyzed only dietary intake, they found a $6 \%$ reduction in $\mathrm{BC}$ risk per one-tenth increment of the $n-3 / n-6$ ratio. The association between the blood phospholipid $n-3 / n-6$ ratio and $\mathrm{BC}$ risk (in four studies only) did not reach statistical significance. The lack of a significant relationship between $\mathrm{BC}$ risk and blood $\mathrm{n}-3 / \mathrm{n}-6$ ratio is not unexpected, because n-3 and n-6 measured in phospholipids do not accurately reflect dietary intake. Several factors (discussed in the next paragraph) interfere with the levels of both $n-3$ and n- 6 in each class of phospholipids. In addition, the fatty acid composition of each phospholipid is not identical: it differs in serum, red cell membranes, and mitochondria, for example, and these various phospholipids have a different physiology and a different effect (if any) on cancers [7]. There are nonetheless correlations between dietary $n-6$ and $n-3$ and the corresponding fatty acids in blood and cells, and it is not illogical to pool data from diet and blood when analyzing relationships with $\mathrm{BC}$ risk. It is, however, crucial to bear these differences in mind when interpreting the results, and potential confounders should be included in the analyses if possible; that is, if they have been recorded in a timely and accurate fashion. In the next section, we highlight some lifestyle, environmental, and pharmacological factors that influence $n-3 / n-6$ ratios, and examine their relationships with $\mathrm{BC}$ risk. In most studies included in the meta-analysis by Yang et al., these factors were not measured, which is likely to have weakened the associations between $n-3 / n-6$ ratio and $\mathrm{BC}$ risk.

\section{Factors influencing $n-3 / n-6$ ratios and $B C$ risk}

Among the main risk factors of $\mathrm{BC}$, estrogen exposure, lack of physical exercise and being overweight are well known [1-3].

Studies support an association between endogenous sex hormone levels and $\mathrm{BC}$ risk for post-menopausal women, whereas the association is less clear for premenopausal women [11]. One possible explanation is that the high estrogen levels present before menopause increase blood marine $n-3$ [12], which in turn may partly counteract the effect of estrogens, as marine $n-3$ are protective $[5,7,10]$.

Besides increased intake of $n-3$ and decreased intake of $n-6$ through consumption of foods rich in $n-3$ and poor in n-6 [7-9], other substances are known to affect the n-3/ $n-6$ ratio. The endogenous synthesis of marine $n-3$ from their plant substrate alpha-linolenic acid (ALA) is stimulated by the plant pigment polyphenols found in purple fruits such as grapes (and wines), plums, and blueberries [13-15]. Polyphenol flavonoids increase marine $n-3$ by $30 \%$ without altering $n-6$ levels, resulting in a significant increase in the $n-3 / n-6$ ratio. As expected from the above data, flavonoids are associated with a decreased $\mathrm{BC}$ risk [16]. These data are encouraging, as it is difficult to accurately determine the intake of each flavonoid, and this probably weakens the association between specific flavonoids and $\mathrm{BC}$ risk. In addition, the bioavailability and biological effect of flavonoids are dependent on many factors, including the gut microbiota [17], which again is likely to weaken the associations. A typical example of such complexity is provided by the soy flavonoids.

Soy isoflavones, a major class of phytoestrogens, may reduce $\mathrm{BC}$ risk, but epidemiologic studies have yielded inconsistent results [18]. A meta-analysis suggests that protection is only observed in studies conducted in East Asian and not in western populations [18], suggesting that protection may require that women consume the high levels of soy typical of East Asian diets. In addition, the food source of isoflavones, timing of exposure to isoflavones (starting at or not before adolescence), the woman's menopausal status, and the ability of the gut microbiota to transform isoflavones into equol probably modify the association between soy isoflavones and BC risk. Equol is more biologically active (that is, more antiestrogenic) than dietary isoflavones, but only about $30 \%$ of women in the USA and Australia are equol producers [19]. Finally, the small studies examining whether equol exposure is associated with $\mathrm{BC}$ risk have produced inconsistent results [20]. Other phytoestrogens more characteristic 
of the western diet are the polyphenol lignans present in seeds, grains, fruits, and vegetables. High dietary lignans or high exposure to enterolignans, the metabolites resulting from transformation by the gut microbiota, are associated with lower BC risk and better survival in post-menopausal BC $[21,22]$. This is not unexpected, as we have shown in rats that lignans increase blood $n-3$ without affecting $n-6$, resulting in a higher $n-3 / n-6$ ratio $[7,13]$.

Another crucial point is the fact that organic plant foods contain more polyphenols than similar conventional foods [23-26]. Organic animal fat also - for instance, milk and milk products - do have a higher $n-3 / n-6$ ratio than conventional products [27-29]. Organic-fed animals mainly consume non-contaminated fresh grass with a high polyphenol content, rather than polyphenol-poor concentrates potentially contaminated with pesticides, and this may partly explain the favorable $n-3 / n-6$ ratio $[30,31]$.

Regarding food contaminants, recent studies have shown a strong association between estrogenic PCBs (polychlorobiphenyls) congeners and $\mathrm{BC}$ risk [32]. In this context, it is crucial to identify 'hidden' groups of women whose occupational exposure to carcinogens is underrepresented in epidemiological studies. Studies have recently shown significant associations between $\mathrm{BC}$ risk and endocrine disruptors in women with specific professional exposure [33]. Endocrine disruptors (particularly phthalates) increase insulin resistance, and the risk of diabetes and obesity [34], all of which increase BC risk [1-3].

Other commonly encountered substances that potentially influence both $n-3 / n-6$ ratio and $B C$ risk are the cholesterol-lowering statins. Statins decrease n-3/n-6 ratio [35], increase insulin resistance and diabetes risk [36], lower cholesterol, and are toxic to mitochondria [37]. Whether or not statins, by modifications of the above processes [35-38], are involved in increased BC risk, remains an area of controversy. Therefore, when weighing up the benefits and potential risks of statins, caution should be applied prior to prescription. Following the same line of reasoning, high-risk women should do everything they can to reduce their risk of insulin resistance, metabolic syndrome and diabetes [1-3]. Beside optimal physical activity, which is a well-known strategy for decreasing both diabetes and $\mathrm{BC}$ [1-3] risks, high fiber intake, high flavonoids, and high n-3 are all inversely associated with diabetes risk. Accordingly, fiber intake, flavonoids [16], and n-3 [5,7,10] are inversely associated with $\mathrm{BC}$ risk. Finally, consumption of foods with a lower glycemic impact - that is, a low glycemic index (GI) - is associated with a lower incidence of diabetes and a lower $\mathrm{BC}$ risk [1-3].

These data are highly consistent, and the combination of high fiber, high n-3/n-6 ratio, high polyphenols, and low-GI foods represents what many experts call a healthy dietary pattern - for instance, the Mediterranean diet - which has been associated with a lower $\mathrm{BC}$ risk and better survival for women with early-stage BC.

\section{Reducing $\mathrm{BC}$ risk}

In summary (see Table 1), the accumulated evidence shows that in addition to genetic predisposition and estrogen exposure, a number of lifestyle, environmental, and pharmacological factors play an important role in BC risk and $\mathrm{BC}$ survival. Optimal physical activity decreases insulin resistance, diabetes risk, and the risk and progression of $\mathrm{BC}$ [39]. Adhering to a healthy dietary pattern - a modernized Mediterranean diet [40], or a similar healthy diet adapted to specific populations, such as the Okinawan diet in East Asians [41] - has been shown to be effective. Emphasis should be given to increasing plant and animal (including marine) $\mathrm{n}-3$, and decreasing plant and animal $\mathrm{n}-6$. High polyphenol consumption, in particular of flavonoids, which increase the synthesis of marine n-3 and result in a higher $n-3 / n-6$ ratio, is associated with lower $\mathrm{BC}$ risk. To reduce insulin resistance and diabetes, which are associated with an increased BC risk, women should increase their consumption of $\mathrm{n}-3$ and fiber and favor low-GI foods. In addition, organic foods have been shown to contain more polyphenols and have a higher $n-3 / n-6$ ratio than non-organic foods. As a higher $n-3 / n-6$ ratio

Table 1 How to reduce breast cancer risk and improve survival after diagnosis

\begin{tabular}{|c|c|}
\hline Item & Recommendations \\
\hline Exposure to sex steroids & Decrease \\
\hline Physical activity & Adopt optimal level ${ }^{1}$ \\
\hline Modernized Mediterranean diet ${ }^{2}$ & Full adherence \\
\hline Plant and marine $n-3$ & Increase $^{3}$ \\
\hline Plant and animal n-6 & Decrease $^{3}$ \\
\hline Polyphenols & Increase $^{3}$ \\
\hline Fiber & Increase $^{3}$ \\
\hline High Gl foods & Decrease $^{3}$ \\
\hline Alcohol (no more than 1 drink/day) & Preferably wine \\
\hline Organic foods (plant and animal sources) & May be beneficial \\
\hline Exposure to endocrine disruptors & Decrease where possible \\
\hline Insulin resistance and diabetic risk & Decrease $^{4}$ \\
\hline Age-associated weight gain & Limit $^{4}$ \\
\hline \multicolumn{2}{|l|}{ Drugs } \\
\hline Cholesterol-lowering statins & Use caution \\
\hline Drugs suspected to increased $B C$ risk & Use caution \\
\hline $\begin{array}{l}\text { Drugs suspected to increased insulin } \\
\text { resistance and diabetic risk }\end{array}$ & Use caution \\
\hline \multicolumn{2}{|c|}{$\begin{array}{l}\text { BC, breast cancer; Gl, glycemic index. } \\
{ }^{1} \text { Tailored to the capacity of each individual. } \\
{ }^{2} \text { Consider an alternative healthy diet in specific populations; Okinawan diet for } \\
\text { East Asians for instance. } \\
{ }^{3} \text { Compared with a western-style diet. } \\
{ }^{4} \text { By adhering to the modernized Mediterranean diet (see text). }\end{array}$} \\
\hline
\end{tabular}


has been associated with decreased $\mathrm{BC}$ risk, consumption of organic foods may be beneficial. Care must be taken to reduce (professional and non-professional) exposure to environmental chemical contaminants. Drugs that decrease the n-3/n-6 ratio, and/or increase insulin resistance and diabetic risk (in particular statins) should be taken with caution.

\section{Conclusions}

National and international cancer associations regularly release anti-cancer guidelines. For instance, every five years the American Cancer Society publishes its Nutrition and Physical Activity Guidelines, which reflect current scientific evidence and focus on recommendations for individual choices regarding diet and physical activity patterns [42]. These Guidelines state: 'for people who do not use tobacco, the most important modifiable determinants of cancer risk are weight control, dietary choices, and levels of physical activity' and 'although genetic susceptibility influences the risk of cancer, most of the variation in cancer risk across populations and among individuals is due to factors that are not inherited'. Regarding $\mathrm{BC}$ specifically, the Guidelines state, 'the best advice to reduce the risk of breast cancer is to engage in regular, intentional physical activity; to minimize lifetime weight gain through the combination of caloric restriction (in part by consuming a diet rich in vegetables and fruits) and regular physical activity; and to avoid or limit intake of alcoholic beverages' [42].

We agree wholeheartedly with this advice. However, we feel it is time to go further and to be more specific. A specific healthy dietary pattern such as the modernized Mediterranean diet, and not simply "consuming a diet rich in vegetables and fruits", should be adopted to decrease $\mathrm{BC}$ risk. This is also an effective way of maintaining a healthy weight, and preventing diabetes and cardiovascular disease. The focus must be on the $n-3 / n-6$ ratio and polyphenols. Organic foods are shown to contain higher levels of these than non-organic foods, and so may be beneficial. Great care should be taken when using drugs that potentially increase $\mathrm{BC}$ risk. This also applies to $\mathrm{BC}$ survivors to prevent recurrence and improve survival [43].

\footnotetext{
Abbreviations

ALA: Alpha-linolenic acid; BC: Breast cancer; Gl: Glycemic index; n-3: Omega-3
} fatty acids; n-6: Omega-6 fatty acids.

\section{Competing interests}

The authors declare that they have no competing interests.

\section{Authors' contributions}

MdeL drafted the manuscript. PS critically revised the manuscript, and gave final approval for publication. Both authors read and approved the final manuscript.

\section{Acknowledgements}

MdeL and PS receive research grants (through Grenoble University School of Medicine) from the European Community and from the Barilla G\&R F.lli Company.
Received: 26 February 2014 Accepted: 26 February 2014

Published: 27 March 2014

\section{References}

1. Matsen $C B$, Neumayer $L A$ : Breast cancer: a review for the general surgeon. JAMA Surg 2013, 148:971-979.

2. Eccles SA, Aboagye EO, Ali S, Anderson AS, Armes J, Berditchevski F, Blaydes JP, Brennan K, Brown NJ, Bryant HE, Bundred NJ, Burchell JM, Campbell AM, Carroll JS, Clarke RB, Coles CE, Cook GJ, Cox A, Curtin NJ, Dekker LV, Silva Idos S, Duffy SW, Easton DF, Eccles DM, Edwards DR, Edwards J, Evans D, Fenlon DF, Flanagan JM, Foster C, et al: Critical research gaps and translational priorities for the successful prevention and treatment of breast cancer. Breast Cancer Res 2013, 15:R92.

3. Breast Cancer Risk Assessment Tool - National Cancer Institute. http://www. cancer.gov/bcrisktool/ (Accessed March 11, 2014).

4. Khaw KT: Dietary fats and breast cancer risk. BMJ 2013, 347:f4518.

5. Zheng JS, Hu XJ, Zhao YM, Yang J, Li D: Intake of fish and marine n-3 polyunsaturated fatty acids and risk of breast cancer: meta-analysis of data from 21 independent prospective cohort studies. BMJ 2013, 346:f3706.

6. Cheraghi Z, Poorolajal J, Hashem T, Esmailnasab N, Doosti Irani A: Effect of body mass index on breast cancer during premenopausal and postmenopausal periods: a meta-analysis. PLoS One 2012, 7:e51446.

7. de Lorgeril M, Salen P: New insights into the health effects of dietary saturated and omega- 6 and omega- 3 polyunsaturated fatty acids. BMC Med 2012, 10:50.

8. Pearce ML, Dayton S: Incidence of cancer in men on a diet high in polyunsaturated fat. Lancet 1971, 1:464-467.

9. de Lorgeril M, Salen P, Martin JL, Monjaud I, Boucher P, Mamelle N: Mediterranean dietary pattern in a randomized trial: prolonged survival and possible reduced cancer rate. Arch Intern Med 1998, 158:1181-1187.

10. Yang B, Ren XL, Fu YQ, Gao JL, Duo L: Ratio of n-3/n-6 PUFAs and risk of breast cancer: a meta-analysis of 274,135 adult females from 11 independent prospective studies. BMC Cancer 2014, 14:105.

11. Kaaks R, Tikk K, Sookthai D, Schock H, Johnson T, Tjønneland A, Olsen A, Overvad K, Clavel-Chapelon F, Dossus L, Baglietto L, Rinaldi S, Chajes V, Romieu I, Boeing H, Schütze M, Trichopoulou A, Lagiou P, Trichopoulos D, Palli D, Sieri S, Tumino R, Ricceri F, Mattiello A, Buckland G, Ramón Quirós J, Sánchez MJ, Amiano P, Chirlaque MD, et al: Premenopausal serum sex hormone levels in relation to breast cancer risk, overall and by hormone receptor status-results from the EPIC cohort. Int J Cancer 2013.

12. Giltay EJ, Gooren LJ, Toorians AW, Katan MB, Zock P: Docosahexaenoic acid concentrations are higher in women than in men because of estrogenic effects. Am J Clin Nutr 2004, 80:1167-1174.

13. Toufektsian MC, Salen P, Laporte F, Tonelli C, de Lorgeril M: Dietary flavonoids increase plasma very long-chain (n-3) fatty acids in rats. J Nutr 2011, 141:37-41.

14. di Giuseppe R, de Lorgeril M, Salen P, Laporte F, Di Castelnuovo A, Krogh V, Siani A, Arnout J, Cappuccio FP, van Dongen M, Donati MB, de Gaetano G, lacoviello L, European Collaborative Group of the IMMIDIET Project: Alcohol consumption and $n-3$ polyunsaturated fatty acids in healthy men and women from 3 European populations. Am J Clin Nutr 2009, 89:354-362.

15. de Lorgeril M, Salen P, Martin JL, Boucher F, de Leiris J: Interactions of wine drinking with omega-3 fatty acids in patients with coronary heart disease: a fish-like effect of moderate wine drinking. Am Heart J 2008, 155:175-181.

16. Hui C, Qi X, Qianyong Z, Xiaoli P, Jundong Z, Mantian M: Flavonoids, flavonoid subclasses and breast cancer risk: a meta-analysis of epidemiologic studies. PLoS One 2013, 8:e54318.

17. van Duynhoven J, Vaughan EE, Jacobs DM, Kemperman RA, van Velzen EJ, Gross G, Roger LC, Possemiers S, Smilde AK, Doré J, Westerhuis JA, Van de Wiele T: Metabolic fate of polyphenols in the human superorganism. Proc Natl Acad Sci U S A 2011, 108:4531-4538.

18. Dong JY, Qin LQ: Soy isoflavones consumption and risk of breast cancer incidence or recurrence: a meta-analysis of prospective studies. Breast Cancer Res Treat 2011, 125:315-323.

19. Setchell KD, Brown NM, Summer S, King EC, Heubi JE, Cole S, Guy T, Hokin $B$ : Dietary factors influence production of the soy isoflavone metabolite s-(-)equol in healthy adults. J Nutr 1950-1958, 2013:143.

20. Minatoya M, Kutomi G, Asakura S, Otokozawa S, Sugiyama Y, Nagata Y, Mori M, Hirata K: Equol, adiponectin, insulin levels and risk of breast cancer. Asian Pac J Cancer Prev 2013, 14:2191-2199. 
21. Touillaud MS, Thiébaut AC, Fournier A, Niravong M, Boutron-Ruault MC, Clavel-Chapelon F: Dietary lignan intake and postmenopausal breast cancer risk by estrogen and progesterone receptor status. $J$ Natl Cancer Inst 2007, 99:475-486.

22. Zaineddin AK, Vrieling A, Buck K, Becker S, Linseisen J, Flesch-Janys D, Kaaks R, Chang-Claude J: Serum enterolactone and postmenopausal breast cancer risk by estrogen, progesterone and herceptin 2 receptor status. Int J Cancer 2012, 130:1401-1410.

23. Dangour AD, Dodhia SK, Hayter A, Hayter A, Aikenhead A, Allen E, Lock C, Uauy R: Comparison of composition (nutrients and other substances) of organically and conventionally produced foodstuffs: a systematic review of the available literature. Report for the Food Standards Age ncy, July 2009, contract number: PAU221. Available from: http://webarchive nationalarchives.gov.uk/20120206100416/http://food.gov.uk/multimedia/ pdfs/organicreviewappendices.pdf (accessed 14 January 2014).

24. Benbrook C, Davis DR, Andrews PK: Methodologic flaws in selecting studies and comparing nutrient concentrations led Dangour et al. to miss the emerging forest amid the trees. Am J Clin Nutr 2009, 90:1700-1701. author reply 1701.

25. Benbrook C, Zhao X, Yanez J, Davies N, Andrews P: New evidence confirms the nutritional superiority of plant-based organic foods. An Organic Center State of Science Review. 2008. Available from: http://www.organic-center.org/ science.nutri.php?action=view\&report_id=126 (accessed 28 January 2014).

26. Hallmann E, Lipowski J, Marszałek K, Rembiałkowska E: The seasonal variation in bioactive compounds content in juice from organic and non-organic tomatoes. Plant Foods Hum Nutr 2013, 68:171-176.

27. Benbrook CM, Butler G, Latif MA, Leifert C, Davis DR: Organic production enhances milk nutritional quality by shifting fatty acid composition: a United States-wide, 18-month study. PLoS One 2013, 8:e82429.

28. Ellis KA, Innocent G, Grove-White D, Cripps P, McLean WG, Howard CV Mihm M: Comparing the fatty acid composition of organic and conventional milk. J Dairy Sci 1938-1950, 2006:89.

29. Tsiplakou E, Kotrotsios V, Hadjigeorgiou I, Zervas G: Differences in sheep and goats milk fatty acid profile between conventional and organic farming systems. J Dairy Res 2010, 77:343-349.

30. Reynaud A, Fraisse D, Cornu A, Farruggia A, Pujos-Guillot E, Besle JM, Martin B, Lamaison JL, Paquet D, Doreau M, Graulet B: Variation in content and composition of phenolic compounds in permanent pastures according to botanical variation. J Agric Food Chem 2010, 58:5485-5494.

31. McAfee AJ, McSorley EM, Cuskelly GJ, Fearon AM, Moss BW, Beattie JA, Wallace JM, Bonham MP, Strain JJ: Red meat from animals offered a grass diet increases plasma and platelet n-3 PUFA in healthy consumers. Br J Nutr 2011, 105:80-89.

32. Recio-Vega R, Velazco-Rodriguez V, Ocampo-Gómez G, Hernandez-Gonzalez S, Ruiz-Flores P, Lopez-Marquez F: Serum levels of polychlorinated biphenyls in Mexican women and breast cancer risk. J App/ Toxicol 2011, 31:270-278.

33. Brophy JT, Keith MM, Watterson A, Park R, Gilbertson M, Maticka-Tyndale E, Beck M, Abu-Zahra H, Schneider K, Reinhartz A, Dematteo R, Luginaah I: Breast cancer risk in relation to occupations with exposure to carcinogens and endocrine disruptors: a Canadian case-control study. Environ Health 2012, 11:87.

34. Stahlhut RW, van Wijngaarden E, Dye TD, Cook S, Swan SH: Concentrations of urinary phthalate metabolites are associated with increased waist circumference and insulin resistance in adult U.S. males. Environ Health Perspect 2007, 115:876-882

35. de Lorgeril M, Salen P, Defaye P, Rabaeus M: Recent findings on the health effects of omega- 3 fatty acids and statins, and their interactions: do statins inhibit omega-3? BMC Med 2013, 11:5.

36. Culver AL, Ockene IS, Balasubramanian R, Olendzki BC, Sepavich DM, Wactawski-Wende J, Manson JE, Qiao Y, Liu S, Merriam PA, Rahilly-Tierny C, Thomas F, Berger JS, Ockene JK, Curb JD, Ma Y: Statin use and risk of diabetes mellitus in postmenopausal women in the Women's Health Initiative. Arch Intern Med 2012, 172:144-152.

37. Larsen S, Stride N, Hey-Mogensen M, Hansen CN, Bang LE, Bundgaard H, Nielsen LB, Helge JW, Dela F: Simvastatin effects on skeletal muscle: relation to decreased mitochondrial function and glucose intolerance. J Am Coll Cardiol 2013, 61:44-53.

38. Wallace DC: Mitochondria and cancer. Nat Rev Cancer 2012, 12:685-698.

39. McTiernan A, Kooperberg C, White E, Wilcox S, Coates R, Adams-Campbell LL, Woods N, Ockene J, Women's Health Initiative Cohort Study: Women's Health Initiative Cohort Study. Recreational physical activity and the risk of breast cancer in postmenopausal women: the Women's Health Initiative Cohort Study. JAMA 2003, 290:1331-1336.

40. de Lorgeril M: Mediterranean diet and cardiovascular disease: historical perspective and latest evidence. Curr Atheroscler Rep 2013, 15:370.

41. Salen $P$, de Lorgeril M: The Okinawan diet: a modern view of an ancestral healthy lifestyle. World Rev Nutr Diet 2011, 102:114-123.

42. Kushi LH, Doyle C, McCullough M, Rock CL, Demark-Wahnefried W, Bandera EV, Gapstur S, Patel AV, Andrews K, Gansler T, American Cancer Society 2010 Nutrition and Physical Activity Guidelines Advisory Committee: American Cancer Society 2010 Nutrition and Physical Activity Guidelines Advisory Committee. American Cancer Society Guidelines on nutrition and physical activity for cancer prevention: reducing the risk of cancer with healthy food choices and physical activity. CA Cancer J Clin 2012, 62:30-67.

43. Wolin KY, Colditz GA: Cancer and beyond: healthy lifestyle choices for cancer survivors. J Natl Cancer Inst 2013, 105:593-594.

doi:10.1186/1741-7015-12-54

Cite this article as: de Lorgeril and Salen: Helping women to good health: breast cancer, omega-3/omega- 6 lipids, and related lifestyle factors. BMC Medicine 2014 12:54.

\section{Submit your next manuscript to BioMed Central and take full advantage of:}

- Convenient online submission

- Thorough peer review

- No space constraints or color figure charges

- Immediate publication on acceptance

- Inclusion in PubMed, CAS, Scopus and Google Scholar

- Research which is freely available for redistribution

Submit your manuscript at www.biomedcentral.com/submit
C) Biomed Central 